\title{
Body Scanner e o Direito de Personalidade
}

\section{Ana Carolina Squadri Santanna}

Mestranda em Direito na Uerj. Procuradora Federal. anasquadri@bol.com.br

\section{Resumo}

0 presente artigo tem como escopo estudar a possibilidade de 0 Estado exercer sua atribuição de garantir a segurança pública na atual conjuntura de ameaça terrorista, sem que com isso sejam violados direitos humanos. 0 estudo, porém, fica restrito à análise do uso indiscriminado do apareIho body scanner em aeroportos. Para verificar a medida de atuação do Estado na esfera privada é necessário confrontar princípios assegurados tanto na ordem internacional quanto na maioria dos ordenamentos jurídicos, como a proteção à ordem e à segurança e princípios referentes ao direito de personalidade, como a integridade física e a moral. Como ponto de partida, entendeu-se que o titular de direitos humanos é um sujeito com suas peculiaridades que o faz diferente dos demais. Logo, suas características pessoais devem ser levadas em consideração pelo Estado para que não haja violação da dignidade da pessoa humana. A metodologia de trabalho baseou-se em pesquisa de periódicos e sites especializados na área de aviação e de radiologia, além de bibliografia jurídica.

Palavras-chave: Direitos humanos. Segurança pública. Direitos fundamentais. Integridade física e moral. Ponderação de interesses.

\section{BODY SCANNER AND RIGHT OF PERSONALITY}

\begin{abstract}
This work has the objective to study the possibility of the State to exercise its allocation to ensure public safety in the current terrorist threat, without thereby being violated human rights. The study, however, is restricted to the analysis of the indiscriminate use of the apparatus body scanner at airports. To verify the extent of state action in the private sphere is necessary to confront principles provided both at the international as in most jurisdictions, as the protection order and safety and principles for the right of personality, as the physical and moral. As a starting point, it was understood that
\end{abstract}


the holder of human rights is a subject with its peculiarities that make it different from others. Soon, their personal characteristics should be taken into consideration by the state so there is no violation of human dignity. The methodology was based on research journals and websites specializing in the area of aviation and radiology, as well as legal literature.

Keywords: Human rights. Public safety. Fundamental rights. Physical and moral integrity. Balancing of interests.

\section{Sumário}

1 Introdução. 2 Declaração Universal de Direitos Humanos. 3 A Dignidade da Pessoa Humana e os Direitos Fundamentais. 4 Colisão entre direitos fundamentais. 5 Conclusão. 6 Referências 


\section{INTRODUÇÃO}

Desde os ataques de 11 de setembro de 2001, ocorridos nos Estados Unidos, as medidas de segurança postas em prática nos aeroportos em diversos Estados têm sido cada vez mais rigorosas. Outro fato propulsor para o aumento do rigor foi a tentativa de explosão de um avião durante o voo transatlântico Northwest Airlines 253, que seguia de Amsterdã para Detroit (EUA). ${ }^{1}$

Como exemplo de normas de segurança mais rigorosas, foi a proibição de transportar objeto cortante ou perfurante em bagagem de mão e, sendo voo internacional, proibiu-se o transporte de líquidos a bordo do avião, conforme orientação da International Civil Aviation Organization (Icao). ${ }^{2}$ Essas medidas restritivas de direitos pretendem prevenir atos ilícitos em voo (security) em aeroportos e em aeronaves, haja vista os incidentes nos últimos anos.

Em 2010 foi introduzida no Reino Unido a mais recente inovação em security, que é o scanner do corpo humano, denominado body scanner. Com esse sistema de proteção, o passageiro é escolhido conforme critério

1 "Em pleno voo um passageiro identificado como Abdul Farouk Abdulmutallaba, de 23 anos e nacionalidade nigeriana, fez despoletar um engenho explosivo consistindo numa mistura de pó inflamável e líquido (inicialmente suposto ser panchão) cerca de 20 minutos antes de o avião aterrissar. $\mathrm{O}$ suspeito aparentemente bateu num pacote de pó na sua perna ou virilha, e usou uma seringa com produtos químicos para causar uma reacção química, e a parte inferior do seu corpo foi apanhada em fogo. O engenho falhou a detonação. Um passageiro afirmou 'Houve fumo e chamas; foi assustador.' Supõe-se que a substância usada foi tetranitrato de pentaeritritol, um químico altamente explosivo. A aeronave, um Airbus A330-300 tinha 278 pessoas a bordo. Por volta das 12:00 locais, na fase de aterragem, um passageiro tentou explodir alguns petardos de fraca intensidade. $\mathrm{O}$ suspeito, um nigeriano de nome Abdul Mudallad, de 23 anos terá dito às autoridades americanas que havia sido treinado pela Al-Qaeda e o ataque fora uma ordem de Osama Bin Laden. Segundo ele, os explosivos teriam sido fornecidos a ele por militantes do Iêmen, porém há suspeitas de que o nigeriano tenha agido sozinho e apenas se inspirado na organização comandada pelo saudita Osama Bin Laden” In: Enciclopédia Wikipédia. Disponível em: <http://pt.wikipedia. org/wiki/Voo_Northwest_Airlines_253>. Acesso em: 24 out. 2012.

${ }^{2}$ Revista da Icao, vol. 7, n. 1, 2012, p. 16. Disponível em: <http://www.icao.int/publications/ journalsreports/2012/MRTD_Report_Vol7_No1.pdf>. Acesso em: 24 out. 2012. 
pré-estabelecido para identificar pessoas com comportamento suspeito. $\mathrm{O}$ passageiro submetido ao body scanner é conduzido a uma cabine determinada, na qual recebe raios eletromagnéticos, gerando uma imagem em 3-D da pessoa. A vantagem do aparelho é que possibilita visualizar quaisquer armas e drogas, inclusive aquelas ingeridas.

No Brasil, por exemplo, o body scanner é utilizado no Complexo Penitenciário Nelson Hungria $(\mathrm{CPNH})$, na Região Metropolitana de Belo Horizonte, para "varredura corporal, durante o procedimento de revistas dos funcionários e visitantes da unidade prisional”. ${ }^{3}$ De acordo com o secretário de Estado de Defesa Social, Lafayette Andrada, “a utilização da nova tecnologia reduz os constrangimentos da revista e torna a entrada mais ágil, diminuindo o tempo de espera nas filas e aumentando a segurança da unidade no que se refere à entrada de objetos proibidos”. ${ }^{4}$ Desse modo, o procedimento da revista íntima fica suprimida no Complexo Penitenciário, entendendo o governo de Minas Gerais que se trata de uma política de humanização do sistema prisional.

Esse é também o entendimento do Procurador-Geral da Ordem dos Advogados do Brasil no Rio de Janeiro, ao comentar a respeito da introdução do aparelho nos principais aeroportos do Brasil, uma vez que "substitui métodos tradicionais, como a revista por apalpamento e buscas que obrigam o suspeito a se despir, o equipamento pode ser avaliado como menos invasivo". Segundo o representante da OAB, "trata-se de uma medida menos constrangedora do que as que estão em vigor". ${ }^{5}$

No que respeita à infraestrutura aeroportuária, o body scanner está sendo utilizado na aérea de embarque internacional no aeroporto Antonio Carlos Jobim, localizado no Rio de Janeiro. Segundo matéria publicada na Folha de São Paulo, a Polícia Federal informou que "ao refletir o corpo humano e eventuais armas escondidas, as ondas milimétricas

\footnotetext{
${ }^{3}$ Informação extraída da Secretaria de Estado de Defesa Social. Disponível em: <https:// www.seds.mg.gov.br>. Acesso em: 24 out. 2012.

${ }^{4}$ Idem.

${ }^{5}$ Disponível em: <http://portaldaradiologia.com>. Acesso em: 24 out. 2012.
} 
do 'body scanner' podem tornar transparentes camadas leves de roupas. Um receptor coleta os sinais refletidos e os direciona a um computador, responsável por processar os dados e gerar uma imagem tridimensional dos indivíduos escaneados”. Ainda de acordo com informações prestadas pela Polícia Federal, “a utilização do equipamento é rápida, individual e reservada, preservando o cidadão de uma busca pessoal invasiva e mais demorada (...). A aquisição dos ‘body scanners’ foi previamente autorizada pela Comissão Nacional de Energia Nuclear (CNEN), que comprovou ser inofensivo à saúde humana”. ${ }^{6} \mathrm{O}$ uso do aparelho é uma recomendação de organização internacional, segundo a Polícia Federal.

O presente trabalho tem como escopo confrontar o uso do body scanner pelo Estado como um meio de prevenção e combate ao crime - que decorre de princípios consagrados tanto na ordem internacional quanto na ordem interna, como a soberania e a segurança pessoal - com o princípio da dignidade da pessoa humana.

Adianta-se que ao tratar de direitos humanos, é considerado o conceito contemporâneo de cidadania, o qual abrange a especificação do sujeito de direito, isto é, o titular dos direitos humanos é um sujeito com suas peculiaridades que o faz diferente dos demais e por isso o Estado deve respeitar as especificidades de cada indivíduo. O sujeito de direito, portanto, deixa de ser visto em sua abstração e generalidade. ${ }^{7}$

\section{DECLARAÇÃO UNIVERSAL DOS DIREITOS HUMANOS}

Os tratados internacionais de direitos humanos são estudados pelo Direito Internacional dos Direitos Humanos, que é um campo do Direito desenvolvido após as atrocidades cometidas na Segunda Guerra Mundial.

\footnotetext{
6 "Aeroporto do Rio começa a usar scanner corporal; outras 3 cidades terão equipamento", notícia de 7/5/2010, Disponível em: <www.folha.uol.com.br>. Acesso em: 24 out. 2012.

7 Piovesan, 2003.
} 
De acordo com Richard B. Bilder, citado por Flávia Piovesan, “o movimento do direito internacional dos direitos humanos é baseado na concepção de que toda nação tem a obrigação de respeitar os direitos humanos de seus cidadãos e de que todas as nações e a comunidade internacional têm o direito e a responsabilidade de protestar, se um Estado não cumprir suas obrigações."

Dessa forma, a proteção dos direitos humanos não deve ficar restrita no âmbito do Estado, vez que se trata de tema de interesse internacional. Com isso, alguns institutos sofreram uma releitura, como a noção de soberania absoluta do Estado, que passa por um processo de relativização, além da ideia de que o indivíduo passa a ser sujeito de direito na esfera internacional. Logo, os problemas enfrentados pelos indivíduos passam a ser um interesse da ordem internacional.

Inspirado pela ideia de internacionalização dos direitos humanos, em 1948 é concebida a Declaração Universal dos Direitos Humanos, sem que tenha sido feita qualquer reserva ou questionamento acerca dos princípios ali previstos. De acordo com Francisco Resek, não há como afirmar se antes da criação das Nações Unidas havia uma "preocupação consciente e organizada” com os direitos humanos no âmbito do Direito Internacional. ${ }^{9}$

Entende Flávia Piovesan que a Declaração de 1948 “introduz a concepção contemporânea de direitos humanos, marcada pela universalidade e indivisibilidade desses direitos. Universalidade porque a condição de pessoa é o requisito único e exclusivo para a titularidade de direitos, sendo

\footnotetext{
${ }^{8}$ Idem. p. 31.

${ }^{9}$ Resek, 2005, p. 218.
} 
a dignidade humana o fundamento dos direitos humanos." ${ }^{10}$ Cumpre destacar que atualmente retoma-se o debate acerca da universalidade ou do relativismo cultural dos direitos humanos. ${ }^{11}$

Outra característica da Declaração de 1948 é a consagração inédita dos direitos econômicos, sociais e culturais, como o direito ao trabalho, por exemplo. Com a previsão de novos direitos considerados imprescindíveis para a vida humana, entende-se que uma geração de direitos não substitui a outra, mas interagem entre si.

Assim, os direitos de primeira geração, que correspondem aos direitos civis e políticos, os de segunda, que correspondem aos direitos sociais, econômicos e culturais e os de terceira, que prestigiam o direito ao desenvolvimento, à paz, traduzindo o valor da solidariedade, passam a ser entendidos como uma unidade interdependente, inter-relacionada e indivisível. Isso significa que não há como garantir um direito à liberdade sem assegurar o direito à igualdade. ${ }^{12}$

A relevância da consagração desses direitos na ordem internacional é devido a sua significativa influência nas Constituições, como também nas decisões das Cortes.

\footnotetext{
${ }^{10}$ Idem, p. 34.

11 "Para os universalistas, os direitos humanos decorrem da dignidade humana, enquanto valor intrínseco à condição humana. Defende-se, nessa perspectiva, o mínimo ético irredutível - ainda que possa se discutir o alcance deste 'mínimo ético'. Para os relativistas, a noção de direitos está estritamente relacionada ao sistema político, econômico, cultural, social e moral vigente em determinada sociedade” (Piovesan et al., 2008, p. 673).

${ }^{12}$ Piovesan, 2003, p. 37.
} 
A partir da promulgação da Declaração Universal, foram celebrados inúmeros tratados internacionais concernentes à proteção dos direitos humanos, como o Pacto Internacional dos Direitos Civis e Políticos, o Pacto Internacional dos Direitos Econômicos, Sociais e Culturais, a Convenção contra a Tortura, dentre outros. ${ }^{13}$

Também pode ser citada como exemplo a Convenção Americana sobre Direitos Humanos, denominada Pacto de San José da Costa Rica, concluída em 22 de novembro de 1969, a qual trata dos direitos de personalidade, do princípio da anterioridade da lei penal, da liberdade de expressão, etc.

No que diz respeito aos direitos de personalidade, o Pacto Internacional dos Direitos Civis e Políticos prevê que "ninguém poderá ser objeto de ingerências arbitrárias ou ilegais em sua vida privada, em sua família, em seu domicílio ou em sua correspondência, nem de ofensas ilegais a sua honra e reputação" (artigo 17). ${ }^{14}$

Com relação ao direito à liberdade de religião, o próprio Pacto já faz uma exceção à liberdade, estabelecendo que "a liberdade de manifestar a própria religião ou crença estará sujeita apenas a limitações previstas em lei e que se façam necessárias para proteger a segurança, a ordem, a saúde ou a moral públicas ou os direitos e as liberdades das demais pessoas”.

Dessa forma, os direitos de personalidade, como o direito à intimidade e à integridade moral, são considerados valores fundamentais para o ser humano e a garantia de sua respeitabilidade está amparada pelo ordenamento internacional.

\footnotetext{
13 “Ao lado do sistema normativo global, surge o sistema normativo regional de proteção, que busca internacionalizar os direitos humanos no plano regional de proteção, particularmente na Europa, América e África. (...) Os sistemas global e regional não são dicotômicos, mas complementares" (Piovesan, 2003, p. 40).

${ }^{14}$ Disponível em: <http://portal.mj.gov.br/sedh/ct/legis_intern/pacto_dir_politicos.htm>. Acesso em: 6 nov. 2012.
} 
Ocorre que o direito à segurança também está consagrado no Pacto Internacional de Direitos Civis e Políticos, visto que a liberdade pode ser restringida para "proteger a segurança nacional, a ordem, a saúde ou a moral pública”, conforme prevê o artigo 19.

Desse modo, indaga-se como se garante o direito de personalidade numa situação de confronto com o direito à segurança.

\section{A DIGNIDADE DA PESSOA HUMANA E OS DIREITOS FUNDAMENTAIS}

Primeiramente cabe destacar que não é possível obter uma definição clara do que seja dignidade da pessoa humana. Uma das dificuldades decorre de sua referência como um valor do ser humano e não como um aspecto específico da existência humana, como a integridade física.

Além disso, fixar um conceito de dignidade humana não se harmoniza com a ideia de uma sociedade pluralista e com diversidade de valores, que devem ser respeitados num Estado Democrático. Sendo assim, trata-se de um conceito em constante processo de desenvolvimento e construção, de maneira que esteja em harmonia com as necessidades de seu tempo.

Inspirado na Declaração Universal dos Direitos Humanos, o Tribunal Constitucional da Espanha atribui um significado à dignidade no seguinte sentido: "É um valor espiritual e moral inerente à pessoa, que se manifesta singularmente na autodeterminação consciente e responsável da própria vida e que leva consigo a pretensão ao respeito por parte dos demais." 15

${ }^{15}$ Sarlet, 2012, p. 54. 
Considerando o que dispõe a Declaração Universal e o entendimento da doutrina majoritária, o elemento nuclear da dignidade da pessoa humana é a autonomia e a autodeterminação do indivíduo. Ressalta-se que a autodeterminação refere-se a uma capacidade em potencial do ser humano de conduzir sua vida de acordo com suas próprias crenças. Desse modo, o absolutamente incapaz também possui dignidade como qualquer outro ser humano.

$\mathrm{Na}$ lição de Ernst Benda, a noção de dignidade humana deve ser aferida com a análise do caso concreto, verificando-se a conduta do ente estatal e de cada indivíduo. ${ }^{16}$

Após a barbárie do nazismo e do fascismo, o princípio da dignidade da pessoa humana foi consagrado no âmbito internacional, bem como no Direito Interno, como "valor máximo dos ordenamentos jurídicos e princípio orientador da atuação estatal e dos organismos internacionais."17

O princípio da dignidade da pessoa humana foi introduzido no Direito Interno por meio das Constituições, visando com isso a legitimar a atuação do Estado, além de jurisdicionalizar possibilitar a tutela jurisdicional de um princípio de direito humano.

Como exemplo, a Constituição Federal brasileira de 1988 previu o princípio da dignidade no artigo $1^{\circ}$, inciso III, sendo desdobrado analiticamente ao longo do texto constitucional ${ }^{18}$.

De acordo com Ingo Wolfgang Sarlet, "uma das funções exercidas pelo princípio fundamental da dignidade da pessoa humana reside justamente no fato de ser, simultaneamente, elemento que confere unidade de sentido e legitimidade a uma determinada ordem constitucio-

${ }^{16}$ E. Benda. Die Menschenwürde ist Unantastbar. In: ARSP, no 22 (1984), p. 23 apud idem p. 58. ${ }^{17}$ Barcellos, 2002, p. 108.

${ }^{18}$ Idem, p. 110. 
nal, constituindo-se, pelo menos de acordo com a significativa fórmula de Haverkate, no "ponto de Arquimedes do estado constitucional."”19 Sendo assim, além de possuir a função de bússola ao ordenamento como um todo, de maneira que a interpretação das normas e a hermenêutica estejam em conformidade com o princípio da dignidade da pessoa humana, também fundamenta as ações do Estado.

Dessa forma, o ordenamento jurídico que prevê a dignidade humana como ponto culminante do sistema deve aplicar o postulado in dúbio pro libertate, além da escolha pelo entendimento mais favorável ao imperativo da dignidade, dentre as possibilidades cabíveis de interpretação e de aplicação do Direito. ${ }^{20}$

Embora, no entanto, o princípio da dignidade da pessoa humana seja "elemento informador dos direitos e garantias fundamentais", estes entendidos como princípios constitucionais, "também é certo que isto não significa que todos os direitos fundamentais (até mesmo pelo fato de que sempre poderá haver direitos fundamentais em sentido eminentemente formal ou cuja fundamentalidade encontra-se diretamente lastreada em outros valores e opções do constituinte) sejam uma decorrência direta da dignidade da pessoa humana." 21

Ao prever a dignidade da pessoa como um princípio fundamental do Estado, reconhece o constituinte que "é o Estado que existe em função da pessoa humana, e não o contrário, já que o ser humano constitui a finalidade precípua, e não meio da atividade estatal." ${ }^{22}$ Logo, é o Estado que deve adequar sua atividade para garantir o respeito à dignidade humana, para que o indivíduo possa desfrutar da sua liberdade e privacidade sem

\footnotetext{
${ }^{19}$ Sarlet, 2012, p. 143.

${ }^{20}$ Sarlet, 2012, p. 150.

${ }^{21}$ Idem, p. 148.

${ }^{22}$ Idem, p. 80.
} 
ser molestado pelo ente público. Considerando que o homem está à frente do Estado, seus direitos subjetivos são mais relevantes em comparação com os deveres objetivos do ente público. ${ }^{23}$

Ressalta-se que o respeito à dignidade humana não depende de sua previsão no ordenamento positivo, porém a sua efetiva proteção irá depender do quanto é reconhecido pelo sistema jurídico interno. Apesar de a dignidade ser inerente ao ser humano, sem desconsiderar outras formas de vida, é relevante a sua previsão normativa para que seja considerada um direito subjetivo.

No entendimento de Ingo Wolfgang Sarlet, os direitos fundamentais não decorrem necessariamente dos direitos humanos. Isso porque os direitos fundamentais integram o Direito Positivo, podendo estar previsto expressa ou implicitamente na Constituição. Já os direitos humanos são universais e indivisíveis, possuem assento no Direito Internacional ${ }^{24}$ e podem ou não ser incorporados ao Direito interno como princípio fundamental. ${ }^{25}$

Quanto ao conteúdo do princípio da dignidade humana, princípio quase sempre presente nas Constituições, pode-se afirmar que está relacionado com os direitos humanos. Segundo Ana Paula de Barcellos,

\footnotetext{
${ }^{23}$ Barbosa-Fohrmann; Torres, 2012, p. 383.

24 "Universalidade porque clama pela extensão universal dos direitos humanos, sob a crença de que a condição de pessoa é o requisito único para a titularidade de direitos, considerando o ser humano como um ser essencialmente moral, dotado de unicidade existencial e dignidade, esta como valor intrínseco à condição humana. Indivisibilidade porque a garantia dos direitos civis e políticos é condição para a observância dos direitos sociais, econômicos e culturais e vice-versa. Quando um deles é violado, os demais também o são. Os direitos humanos compõem, assim, uma unidade indivisível, interdependente e inter-relacionada, capaz de conjugar o catálogo de direitos civis e políticos com o catálogo de direitos sociais, econômicos e culturais" (Barbosa-Fohrmann; Torres, 2012).
}

${ }^{25}$ No mesmo sentido, ver Barcellos, 2002. 
“terá respeitada sua dignidade o indivíduo cujos direitos fundamentais forem observados e realizados, ainda que a dignidade não se esgote neles." 26

Considerando que os direitos fundamentais não decorrem necessariamente dos direitos humanos, o princípio da dignidade da pessoa humana não está incluído no rol dos direitos e garantias fundamentais na Constituição Brasileira. Vejamos o comentário a seguir que trata da Lei Fundamental da Alemanha:

Em consequência da especialidade da estrutura normativa, a dignidade humana se diferencia qualitativamente de outros direitos fundamentais. Os direitos fundamentais podem ser limitados. Mas a dignidade humana (art. $1^{\circ}, \S 1^{\circ}$, da LF) não é limitável em vista do seu caráter absoluto. Na verdade, ela á um princípio fundamental, e, não, um direito fundamental. Ela é a garantia essencial da LF, a medida suprema para o exercício do poder estatal e influencia tanto a compreensão dos direitos fundamentais como a compreensão de todo o ordenamento constitu-

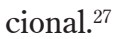

Logo, o artigo $1^{0}$ da Constituição Brasileira estabelece os princípios fundamentais que devem servir de base ao sistema de valores a ser seguido pelo ordenamento jurídico. ${ }^{28}$ Desse modo, a dignidade humana pode ser denominada de "núcleo essencial” da Constituição.

Ressalta-se que o princípio da dignidade da pessoa humana não foi incorporado pela totalidade das Constituições da atualidade, como informa Ingo Wolfgang Sarlet. ${ }^{29}$ Apesar de alguns Estados nãos elevarem

\footnotetext{
${ }^{26}$ Idem, p. 111.

${ }^{27}$ Barbosa-Fohrmann; Torres, 2012, p. 24.

${ }^{28}$ Idem.

${ }^{29}$ Sarlet, 2012.
} 
a dignidade da pessoa humana como princípio fundamental do ordenamento jurídico, o autor acredita que a sua consagração é uma tendência irreversível.

Embora o direito fundamental não tenha origem num valor consagrado pelos direitos humanos, cada direito fundamental deverá ser uma "projeção da dignidade humana," ${ }^{30}$ uns direitos com uma intensidade maior do que outros. Assim, os direitos fundamentais dependem da dignidade humana para serem aplicados e a dignidade humana se torna efetiva por meio dos direitos fundamentais.

Ingo Sarlet constata, então, que diante de um caso concreto, o intérprete deve verificar se há uma ofensa direta a algum direito fundamental específico, tendo em vista que a dignidade humana não é um direito subjetivo, mas somente um princípio orientador do sistema como um todo. Ademais, isso reduz a margem de uma interpretação demasiadamente vaga. ${ }^{31}$

No que se refere à proteção à integridade física, a grande maioria das Constituições e tratados internacionais inclui essa proteção no rol de direitos e garantias.

De acordo com Luís Roberto Barroso, o reconhecimento dos direitos de personalidade ficou fortalecido após a Segunda Guerra Mundial, constituindo-se em um direito que emana diretamente do princípio da dignidade da pessoa humana. ${ }^{32}$

Uma das características dos direitos de personalidade é a sua titularidade atribuída a todo ser humano, sendo oponíveis à coletividade e ao Estado. Sendo assim, além da integridade física, o Estado deve zelar pela integridade psicológica ou pela honra do indivíduo.

\footnotetext{
${ }^{30}$ Idem, p. 155.

${ }^{31}$ Sarlet, 2012.

${ }^{32}$ Barroso, 2005, p. 94-95.
} 
Outra característica do direito de personalidade é que nem sempre a sua violação repercute um prejuízo mensurável em valores, o que enseja numa reparação diversa da indenização. Por isso deve haver uma preocupação maior com a prevenção do dano à personalidade, tendo em vista que pode ser de tal intensidade que não há remédio que o repare.

Os direitos de personalidade podem ser divididos em dois grupos: direito à integridade física e direito à integridade moral, que incluem o “direito à honra, à liberdade, à vida privada, à intimidade, à imagem, ao nome e o direito moral do autor, dentre outros." 33

José Afonso da Silva define o direito à privacidade como "o conjunto de informação acerca do indivíduo que ele pode decidir manter sob seu exclusivo controle, ou comunicar, decidindo a quem, quando, onde e em que condições, sem a isso poder ser legalmente sujeito.”34

No âmbito internacional, o Pacto de San José da Costa Rica prevê no artigo 5․ 1 que "toda pessoa tem direito a que se respeite sua integridade física, psíquica e moral”35. No Brasil, a Constituição Federal previu a garantia dos direitos de personalidade no artigo $5^{\circ}$, inciso X, estabelecendo que "são invioláveis a intimidade, a vida privada, a honra e a imagem das pessoas, assegurado o direito à indenização pelo dano material ou moral decorrente de sua violação”.

\footnotetext{
${ }^{33}$ Idem, p. 96.

${ }^{34}$ Silva, 1999, p. 209.

${ }^{35}$ Disponível em: <http://www.pge.sp.gov.br/centrodeestudos/bibliotecavirtual/instrumentos/sanjose.htm>. Acesso em: 7 nov. 2012. "A convenção internacional procura consolidar entre os países americanos um regime de liberdade pessoal e de justiça social, fundado no respeito aos direitos humanos essenciais, independentemente do país onde a pessoa resida ou tenha nascido. O Pacto baseia-se na Declaração Universal dos Direitos Humanos, que compreende o ideal do ser humano livre, isento do temor e da miséria e sob condições que lhe permitam gozar dos seus direitos econômicos, sociais e culturais, bem como dos seus direitos civis e políticos." <www.stf.jus.br>. Acesso em: 7 nov. 2012.
} 
O direito à honra, especificamente, visa a proteger a "dignidade pessoal do indivíduo, sua reputação diante de si próprio e do meio social no qual está inserido.”36

Já o direito à imagem "protege a representação física do corpo humano ou de qualquer de suas partes, ou ainda de traços característicos da pessoa pelos quais ela possa ser reconhecida." ${ }^{37}$ A reprodução da imagem deve ser autorizada pelo indivíduo, sob pena de violação ao direito fundamental. Tanto a doutrina quanto a jurisprudência, porém, admitem alguns limites para a proteção do direito à imagem, como a imagem divulgada em processo judicial, em publicação científica, além da informação jornalística.

A respeito de restrições a direitos fundamentais, somente normas de hierarquia constitucional podem restringir direitos dessa natureza. ${ }^{38}$ Admitem-se restrições estabelecidas por lei infraconstitucional, quando a Constituição assim previr. Trata-se das restrições indiretamente constitucionais.

Enfim, a dignidade da pessoa humana e os direitos fundamentais limitam a atuação do poder público no exercício da atividade estatal. Os direitos da personalidade, considerados uma emanação da dignidade da pessoa humana, estão previstos em tratados internacionais, bem como nas Constituições dos Estados Democráticos, como ocorre no Brasil. Inserido num sistema jurídico nacional, os direitos da personalidade ganham status de direitos fundamentais, os quais devem pautar a atuação da coletividade e do Estado.

\footnotetext{
${ }^{36}$ Barroso, 2005, p. 98.

${ }^{37}$ Idem, p. 102.

${ }^{38}$ Barcellos, 2002.
} 


\section{COLISÃO ENTRE DIREITOS FUNDAMENTAIS}

A interpretação dos direitos fundamentais não é de todo simples, visto que os princípios são designados como comandos de otimização, ${ }^{39}$ ao contrário das regras, que são comandos de definição, pois ou são válidas e se aplicam ou não se aplicam. Já os princípios devem ser aplicados na maior medida possível, conforme o caso concreto.

$\mathrm{Na}$ aplicação dos princípios pode haver uma colisão entre eles, sendo a ponderação necessária para se fazer uma escolha racionalmente fundamentada. Além disso, deve-se também optar pelos meios mais adequados para a realização do princípio, de modo que cause "menor prejuízo aos demais princípios não prevalentes." ${ }^{40}$

Sob a influência da doutrina alemã, os juristas brasileiros desenvolveram estudos acerca dos princípios da proporcionalidade e da razoabilidade, que se assemelham à ponderação dos princípios. ${ }^{41}$ Nas palavras de Gilmar Ferreira Mendes, o princípio da proporcionalidade é uma típica manifestação do excesso de poder, "que se revela mediante contrariedade, incongruência e irrazoabilidade ou inadequação entre meios e fins." ${ }^{42}$ No Direito Constitucional alemão o princípio da proporcionalidade decorre do estabelecimento do Estado de Direito, pois não há norma escrita acerca da proibição do excesso de poder.

No Brasil, a primeira referência ao princípio da proporcionalidade no Supremo Tribunal Federal ocorreu num julgamento em que se alegava a proteção ao direito de propriedade. ${ }^{43}$

\footnotetext{
${ }^{39}$ Idem.

${ }^{40}$ Idem, p. 120.

${ }^{41}$ Idem.

${ }^{42}$ Mendes, 2004, p. 47.

43 “O poder de taxar não pode chegar à desmedida do poder de destruir, uma vez que aquele somente pode ser exercido dentro dos limites que o tornem compatível com a liberdade de trabalho, comércio e da indústria e com o direito de propriedade. É um poder, cujo exercício
} 
No julgamento em que se enfrentou a colisão entre o direito à saúde e a ordem econômica com base na livre iniciativa, o Supremo Tribunal Federal decidiu que o Estado deve "aparelhar-se adequadamente para a realização de suas atividades, de forma a satisfazer o interesse público sem causar prejuízo a bens jurídicos constitucionalmente protegidos," ${ }^{44}$ de modo que o direito fundamental do indivíduo não seja mitigado pelo interesse político-econômico.

Logo, evidencia-se que o princípio da proporcionalidade é um mecanismo de aferição de legitimidade dos atos do poder público, servindo de "postulado básico de contenção dos excessos" 45 do Estado. $\mathrm{O}$ Estado Democrático de Direito não admite o excesso e o arbítrio do poder público, devendo ter como fundamento de ordem constitucional a garantia do devido processo legal. ${ }^{46}$

não deve ir até ao abuso, o excesso, o desvio, sendo aplicável, ainda aqui, a doutrina fecunda do 'détournement de pouvoir'. Não há que estranhar a invocação dessa doutrina ao propósito da inconstitucionalidade, quando os julgados têm proclamado que o conflito entre a norma comum e o preceito da Lei Maior pode se acender não somente considerando a letra do texto, como também, e principalmente, o espírito do dispositivo invocado” (Idem, p. 51).

${ }^{44}$ Esse julgamento foi proferido no pedido de suspensão de segurança formulado pela União Federal contra decisão do Tribunal Regional Federal da $1^{\text {a }}$ Região que suspendeu a exigência pelo Decreto n. 2.637, de 25/6/98, da venda de 20 unidades de cigarro numa embalagem. (Suspensão de Segurança no ${ }^{\circ}$ 1.320, DJ 14/4/1999). De acordo com a decisão, no que se refere ao direito à saúde "na realidade, a redução do número de cigarros em cada embalagem poderia ter o efeito de condicionar o comportamento do fumante, estimulando-o, psicologicamente, a diminuir o consumo diário desse produto. Daí a observação constante do parecer elaborado pelo eminente professor Celso Antônio Bandeira de Mello (fls. 170): "Notoriamente, o conteúdo do maço ou carteira de cigarro serve de referência para o consumo diário dos fumantes (todos que fumam bem o sabem) e de alerta para que se mantenham dentre de certos limites. Cumpre psicologicamente a função de delimitar um ponto a não ser ultrapassado. Não raro, os que querem melhor controlar-se ou diminuir o número de cigarros fumados servem-se de cigarreiras que preenchem com quantidade inferior à vintena, no afã de reduzir paulatinamente a quantidade de unidades por dia (...). Donde, embalagens com quantidade algo inferior à vintena concorrem na mesma direção estimativa das campanhas contra o fumo, presumidamente defensivas da saúde, ao passo que a obrigatoriedade da vintena imposta pelo decreto-lei e normas a ele subalternas contradita tal orientação."

${ }^{45}$ Mendes, op. cit., p. 64.

${ }^{46}$ Stumm, Raquel Denize. Princípio da proporcionalidade no Direito Constitucional Brasileiro. Porto Alegre: Editora Livraria dos Advogados, 1994. p. 159-170. 
Voltando à técnica da ponderação, o intérprete ao visualizar os princípios confrontantes que se referem ao caso em questão, escolherá uma opção, com a prevalência de um princípio, mas que não despreze totalmente os demais. ${ }^{47}$ Dessa forma, realiza-se uma otimização dos princípios e não a exclusão de um para a aplicação de outro, como ocorre com as regras.

De acordo com Robert Alexy, no caso concreto os princípios possuem pesos diferentes, e aquele que possuir maior carga será o prevalecente. $\mathrm{O}$ referido jurista exemplificou a técnica da ponderação de princípios com um julgamento realizado pelo Tribunal Constitucional Federal da Alemanha a respeito da participação de acusado em audiência processual. Em razão de complicações cardiovasculares, o acusado poderia sofrer alguma lesão a sua integridade física durante a audiência.

O exemplo é interessante, pois trata de tema semelhante ao estudado no presente texto, que é o confronto entre a aplicação correta do Direito Penal pelo Estado (segurança pública) e o direito à vida ou à integridade física do acusado, "para cuja proteção a Constituição também obriga o Estado." ${ }^{48}$

Entendeu o Tribunal Constitucional Federal que essa relação "não pode ser solucionada com base em uma precedência absoluta de um desses deveres.” ${ }^{49} \mathrm{O}$ conflito existente deve ser resolvido por meio de um sopesamento entre os princípios conflitantes. Isso porque o Direito Constitucional previu ambos os princípios; caso houvesse previsão somente do direito à integridade física a audiência não poderia ser realizada. A tensão dos princípios significa que um restringe a possibilidade jurídica do outro, de forma que a sua eficácia não seja plena.

\footnotetext{
${ }^{47}$ Barcellos, op. cit., p. 121.

${ }^{48}$ Alexy, 2012, p. 94-95.

${ }^{49}$ Idem.
} 
Em sua decisão, o Tribunal Constitucional utiliza da metáfora do peso para verificar se "os interesses do acusado no caso concreto têm manifestamente um peso significativamente maior que os interesses a cuja preservação a atividade estatal deve servir." ${ }^{0}$ Nesse sentido, propõe-se a formulação de uma "lei de colisão" com o seguinte enunciado: "Se a realização da audiência implica um risco provável e concreto à vida do acusado ou uma possibilidade de dano grave à sua saúde, então a continuação do procedimento lesa seu direito fundamental garantido (...)”. Vê-se que não há uma precedência de um princípio no enunciado, havendo somente o estabelecimento de condições para a verificação de uma violação a um direito fundamental.

Utilizando-se a teoria da ponderação para o caso body scanner nos aeroportos, ao interpretar os princípios em colisão, deve-se estabelecer um enunciado por meio da metáfora dos pesos, tal como proposto pelo Tribunal Constitucional Alemão. Dessa forma, não haverá exclusão de nenhum princípio em confronto, como o direito à segurança pessoal, o direito à integridade física ou o direito à integridade moral, consagrados na Declaração Universal de Direitos Humanos ${ }^{51}$ e na Constituição Federal do Brasil..$^{2}$

\footnotetext{
${ }^{50}$ Idem, p. 97.

51 “Art. III: Toda pessoa tem direito à vida, à liberdade e à segurança pessoal”. Disponível em: $<$ http://portal.mj.gov.br/sedh/ct/legis_intern/ddh_bib_inter_universal.htm>. Acesso em: 5 nov. 2012.

52 “Art. $4^{\circ}$. A República Federativa do Brasil rege-se nas suas relações internacionais pelos seguintes princípios: VI - defesa da paz"; "Art. $5^{\circ}$. Todos são iguais perante a lei, sem distinção de qualquer natureza, garantindo-se aos brasileiros e aos estrangeiros residentes no País a inviolabilidade do direito à vida, à liberdade, à igualdade, à segurança e à propriedade, nos termos seguintes: III - ninguém será submetido a tortura nem a tratamento desumano ou degradante; são invioláveis a intimidade, a vida privada, a honra e a imagem das pessoas, assegurado o direito à indenização pelo dano material ou moral decorrente de sua violação”.
} 
A relevância de não se excluir por completo a aplicação dos princípios em colisão dá-se, primeiramente, pela garantia do uso pelo Estado de maquinários mais modernos para a segurança pública, e segundo, pelo uso do equipamento mais eficaz de uma forma que não viole frontalmente algum direito fundamental. Assim, para garantir a máxima efetividade dos direitos fundamentais, devem-se estabelecer meios menos gravosos de modo que os indivíduos não sintam sua personalidade agredida, com isso deixando de violar direitos individuais resguardados no âmbito internacional e interno.

O resultado da ponderação dos princípios designa uma regra de direito fundamental, como se fosse norma positiva, ${ }^{53}$ esta sim de caráter absoluto.

Outro exemplo conferido por Robert Alexy trata do caso Lebach, julgado pelo Tribunal Constitucional Federal. A decisão teria de enfrentar o seguinte caso: "A emissora de televisão ZDF planejava exibir um documentário chamado 'O assassino de soldados em Lebach.” ${ }^{54} \mathrm{Um}$ dos condenados como cúmplice do crime, todavia, estava prestes a ser libertado da prisão. Sentindo-se violado pela ameaça de exibição do documentário, ajuizou uma ação requerendo a suspensão do programa, sob pena de ver ferido seu direito fundamental de personalidade. O Tribunal Estadual rejeitou seu pedido cautelar, e por sua vez o Tribunal Superior Estadual rejeitou o recurso.

Em sequência foi ajuizada uma reclamação constitucional contra essas decisões. Ao julgar o caso, o Tribunal Constitucional Federal constatou uma situação de confronto entre a proteção da personalidade, principalmente com relação ao direito de ressocialização, e o direito de informar.

\footnotetext{
53 "Ao mesmo tempo ela é uma regra, à qual se podem subsumir os elementos do caso concreto, como se fosse uma norma positiva” (Alexy, 2012, p. 102).

${ }^{54}$ Idem, p. 100.
} 
Considerando que o comando de otimização não visa a julgar inválido um dos princípios fundamentais, por meio do sopesamento, pretendeu-se conferir uma precedência geral da liberdade de informar, atribuindo exceções para que os direitos de personalidade não fossem violados.

Depois dessas etapas de constatação da colisão e da formulação de uma precedência geral, o Tribunal decidiu numa terceira fase da seguinte maneira: "A repetição do noticiário televisivo sobre um grave crime não mais revestido de um interesse atual pela informação que coloca em risco a ressocialização do autor, a proteção da personalidade tem precedência sobre a liberdade de informar, o que, no caso em questão, significa a proibição da veiculação da notícia." ${ }^{55}$ Assim, o direito de informar não é irrestrito, haja vista o direito de ressocialização do indivíduo.

No que diz respeito ao uso do body scanner pelo Estado como instrumento de segurança pública para prevenção e combate ao crime - fundamentado no princípio da soberania, ao repúdio ao terrorismo, no direito à segurança pessoal e no direito à aplicação correta de medida que importe na restrição da liberdade (decorrente do devido processo legal) - pode significar uma colisão ao direito fundamental à integridade moral, tendo em vista que a tecnologia empregada permite a visualização completa do corpo humano, inclusive dos órgãos sexuais dos passageiros inspecionados.

Segundo Antonio Paulo Cachapuz de Medeiros, o Brasil tem demonstrado repúdio, no plano internacional, ao combate ao terrorismo sem observância da Declaração Universal e de tratados que consagram os direitos humanos. ${ }^{56} \mathrm{O}$ referido autor sustenta que

\footnotetext{
${ }^{55}$ Idem, p. 102.

${ }^{56}$ Direito; Cançado Trindade; Pereira (Coords.), 2008, p. 28.
} 
a imperiosa luta contra o terrorismo não pode ser conduzida a expensas do devido processo legal, do respeito aos direitos humanos e às liberdades civis. Qualquer sacrifício das liberdades fundamentais no combate ao terrorismo, ao dar margem a atos arbitrários ou discriminatórios, representaria um retrocesso que viria ao encontro dos interesses dos

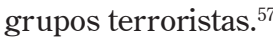

Nos Estados em que a democracia foi estabelecida mais recentemente, prevalece a ideia de que o respeito aos direitos humanos seria um obstáculo na prevenção e no combate ao crime, o que geralmente leva ao desrespeito a direitos fundamentais consagrados na Constituição, como o direito à integridade moral.

Além disso, o respeito aos direitos humanos inclui a proteção do indivíduo e de suas singularidades, sendo insuficiente a garantia da dignidade humana de forma abstrata, como se a humanidade correspondesse a um conjunto de cidadãos homogêneos. ${ }^{58}$

Isso posto, a atuação do Estado no que se refere ao uso do body scanner nos aeroportos não pode se dar de maneira indiscriminada, no sentido de não se levar em consideração as peculiaridades dos indivíduos, como o sexo e a religião, sob pena de ferir os direitos de personalidade, sobretudo o direito à integridade moral.

Assim, cabe ao Estado estabelecer normas procedimentais para o uso do body scanner, estabelecendo meios menos gravosos para a inviolabilidade da personalidade.

${ }^{57}$ Idem, p. 29.

${ }^{58}$ Cf. Sen, Amartya. Human Rights and Asian Values. The New Republic 33-40. In: Henkin, Louis et al. Human Rights. New York: New York Foundation Press, 1999. p. 113-116. 


\section{CONCLUSÃO}

Os passageiros vêm se deparando cada vez mais com medidas de segurança de restrição de direitos, por exemplo, o que pode ou não ser transportado em bagagem de mão. Esses planos de segurança são realizados pelo Estado em razão de seu dever de garantir a segurança da sociedade, como expressão do poder de soberania.

A atuação do Estado sobre a esfera do indivíduo, todavia, não é ilimitada, cabendo ao Direito Internacional o resguardo dos direitos fundamentais, sobretudo aqueles que buscam dar efetividade à dignidade do homem, caso o sistema jurídico interno do país não proteja o indivíduo do arbítrio e do abuso estatal.

No âmbito internacional, a Declaração Universal e diversos tratados internacionais preveem direitos civis e políticos, econômicos, sociais e culturais, os quais prestigiam os valores da liberdade e da igualdade.

No que tange aos direitos de personalidade, que abrange o direito à integridade moral, a Convenção Americana, denominada Pacto de San José da Costa Rica, prevê uma série de direitos de personalidade, como o princípio da anterioridade da lei penal, da liberdade de expressão, a liberdade de religião, dentre outros.

Desse modo, a integridade moral é um valor fundamental para o ser humano, que deve ser respeitado no plano interno pela coletividade e pelo Estado.

Inspiradas na Declaração Universal e nos tratados internacionais, as Constituições dos Estados Democráticos preveem a dignidade da pessoa humana como princípio fundamental que estabelece uma unidade ao sistema, conferindo uma linha de interpretação das normas voltada para a valorização do homem (função objetiva), e ao mesmo tempo confere aos direitos fundamentais o caráter de direito subjetivo. 
Dentre os direitos fundamentais é comum encontrar os direitos de personalidade, que são aqueles que valorizam a autodeterminação do indivíduo e o sigilo acerca do conjunto de informações a seu respeito, sob pena de ferir sua reputação. Destaca-se que somente normas de mesma hierarquia podem restringir os direitos fundamentais, ou quando a Constituição permitir que a lei o faça.

A interpretação dos direitos fundamentais, entretanto, não é simples, tendo em vista tratarem-se de princípios. Como os direitos fundamentais estão catalogados num mesmo patamar hierárquico, pode ocorrer uma situação de confronto entre os princípios na análise do caso concreto.

Numa situação de confronto entre os direitos fundamentais, realiza-se um comando de otimização de maneira que nenhum princípio seja considerado inválido, porém é estabelecido um peso maior a determinado princípio, conforme o caso concreto, que a partir daí se produz uma regra com precedência geral, de maneira que o direito fundamental com maior peso não seja violado. Trata-se da técnica da ponderação de princípios.

Não excluir por completo a aplicação dos princípios em colisão significa, primeiramente, a garantia do uso pelo Estado de maquinários mais modernos para a segurança pública, e segundo, que o uso do equipamento mais eficaz não deve violar frontalmente algum direito fundamental. Assim sendo, para garantir a máxima efetividade dos direitos fundamentais, deve-se estabelecer meios menos vexatórios de modo que os indivíduos não sintam sua personalidade agredida. Com isso deixa-se de violar direitos individuais resguardados no âmbito interno.

Dessa forma, conclui-se que é dever do Estado estabelecer normas procedimentais para o uso do body scanner, estabelecendo meios menos gravosos para a inviolabilidade da personalidade. 


\section{REFERÊNCIAS}

ALEXY, Robert. Teoria dos direitos fundamentais. Tradução Virgílio Afonso da Silva. São Paulo: Editora Malheiros, 2012.

BARBOSA-FOHRMANN, Ana Paula; TORRES, Ricardo Lobo (Coords.). Estudos de Direito Público e Filosofia do Direito: um diálogo entre Brasil e Alemanha. Rio de Janeiro: Renovar, 2011.

. A dignidade humana no Direito Constitucional Alemão. Rio de Janeiro: Editora Lumen Juris, 2012.

BARCELLOS, Ana Paula de. Eficácia jurídica dos princípios constitucionais: o princípio da dignidade humana. Rio de Janeiro: Renovar, 2002.

BARROSO, Luís Roberto. Temas de Direito Constitucional. Tomo III. Rio de Janeiro: Renovar, 2005.

Temas de Direito Constitucional. Tomo II. Rio de Janeiro: Renovar, 2003.

CANO, Ignacio. Direitos humanos, criminalidade e segurança pública. In: VENTURI, Gustavo. Revista de Direitos Humanos: percepções da opinião pública, Secretaria de Direitos Humanos da Presidência da República. Disponível em: <http://portal.mj.gov.br/sedh/biblioteca/livro_percepcoes/percepcoes.pdf $>$. Acesso em: 7 nov. 2012.

DIREITO, Carlos Alberto Menezes; CANÇADO TRINDADE, Antonio Augusto; PEREIRA, Antonio Celso Alves (Coord.). Novas Perspectivas do Direito Internacional Contemporâneo. Estudos em homenagem ao professor Celso D. de Albuquerque Mello. Rio de Janeiro: Renovar, 2008.

DOLINGER, Jacob. Direito Internacional Privado. 9. ed. Rio de Janeiro: Renovar, 2008.

FERNANDEZ, Eusebio. Teoria de la Justicia y Derechos Humanos. Madrid: Editorial Debates, 1991.

GRAU, Eros Roberto. $O$ direito posto e o direito pressuposto. 6. ed. São Paulo: Editora Malheiros, 2005.

JÚNIOR, Nelson Nery. Princípios do Processo Civil na Constituição Federal. 6. ed. São Paulo: Editora Revista dos Tribunais, 2000. 
MEDAUAR, Odete. Direito Administrativo Moderno. 15. ed. São Paulo: Editora Revista dos Tribunais, 2011.

MENDES, Gilmar Ferreira. Direitos fundamentais e controle de constitucionalidade: estudos de direito constitucional. São Paulo: Saraiva, 2004.

OSÓRIO, Fábio Medina; SOUTO, Marcos Juruena Villela (Coord.). Direito Administrativo: estudos em homenagem a Diogo de Figueiredo Moreira Neto. Rio de Janeiro: Editora Lumen Juris, 2006.

PIOVESAN, Flávia. Temas de Direitos Humanos. São Paulo: Max Limonad, 2003.

PIOVESAN, Flávia et al. (Coords.). Novas perspectivas do Direito Internacional Contemporâneo. Estudos em homenagem ao professor Celso D. de Albuquerque Mello. Rio de Janeiro: Renovar, 2008. p. 673.

RESEK, Francisco. Direito Internacional Público. 10 ed. São Paulo: Editora Saraiva, 2005.

SARLET, Ingo Wolfgang. Dignidade da pessoa humana e direitos fundamentais. Porto Alegre: Editora Livraria do Advogado, 2012.

SEN, Amartya. Human Rights and Asian Values. The New Republic 33-40. In: HENKIN, Louis et al. Human Rights. New York: New York Foundation Press, 1999.

SILVA, José Afonso. Curso de direito constitucional positivo. São Paulo: Editora Malheiros, 1999.

STUMM, Raquel Denize. Princípio da proporcionalidade no Direito Constitucional Brasileiro. Porto Alegre: Editora Livraria dos Advogados, 1994.

SUPREMO TRIBUNAL FEDERAL. Disponível em: <www.stf.jus.br >. Acesso em: 7 nov. 2012.

TORRES, Ricardo Lobo. Legitimação dos Direitos Humanos. Rio de Janeiro: Renovar, 2002.

Recebido em 22/3/2013

Revisado em 3/6/2013

Aceito em 18/6/2013 